\title{
Hydrologic feasibility of artificial forestation in the semi-arid Loess Plateau of China
}

\author{
T. T. Jin ${ }^{1,2}$, B. J. Fu ${ }^{1}$, G. H.Liu ${ }^{1}$, and Z. Wang ${ }^{3}$ \\ ${ }^{1}$ State Key Laboratory of Urban and Regional Ecology, Research Center for Eco-Environmental Sciences, \\ Chinese Academy of Sciences, Beijing 100085, China \\ ${ }^{2}$ Graduate University of Chinese Academy of Sciences, Beijing 100039, China \\ ${ }^{3}$ Department of Earth and Environmental Sciences, California State University, Fresno, CA 93740, USA
}

Received: 7 December 2010 - Published in Hydrol. Earth Syst. Sci. Discuss.: 19 January 2011

Revised: 20 July 2011 - Accepted: 8 August 2011 - Published: 15 August 2011

\begin{abstract}
Hydrologic viability, in terms of moisture availability, is fundamental to ecosystem sustainability in arid and semi-arid regions. In this study, we examine the spatial distribution and after-planting variations of soil moisture content (SMC) in black locust tree (Robinia pseudoacacia L.) plantings in the Loess Plateau of China at a regional scale. Thirty sites (5 to $45 \mathrm{yr}$ old) were selected, spanning an area of $300 \mathrm{~km}$ by $190 \mathrm{~km}$ in the northern region of the Shaanxi Province. The SMC was measured to a depth of $100 \mathrm{~cm}$ at intervals of $10 \mathrm{~cm}$. Geographical, topographic and vegetation information was recorded, and soil organic matter was evaluated. The results show that, at the regional scale, SMC spatial variability was most highly correlated with rainfall. The negative relationship between the SMC at a depth of $20-50 \mathrm{~cm}$ and the stand age was stronger than at other depths, although this relationship was not significant at a $5 \%$ level. Watershed analysis shows that the after-planting SMC variation differed depending upon precipitation. The SMC of plantings in areas receiving sufficient precipitation (e.g., mean annual precipitation (MAP) of $617 \mathrm{~mm}$ ) may increase with stand age due to improvements in soil water-holding capacity and waterretention abilities after planting. For areas experiencing water shortages (e.g., MAP $=509 \mathrm{~mm}$ ), evapotranspiration may cause planting soils to dry within the first $20 \mathrm{yr}$ of growth. It is expected that, as arid and semi-arid plantings age, evapotranspiration will decrease, and the soil profile may gradually recover. In extremely dry areas (e.g., MAP $=352 \mathrm{~mm}$ ), the variation in after-planting SMC with stand age was found to be negligible. The MAP can be used as an index to divide the study area into different ecological regions. Afforestation
\end{abstract}

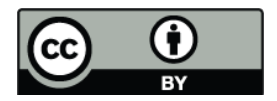

Correspondence to: $\mathrm{B}$. J. Fu (bfu@ rcees.ac.cn) may sequentially exert positive, negative and negligible effects on SMCs with a decrease in the MAP. Therefore, future restoration measures should correspond to the local climate conditions, and the MAP should be a major consideration for the Loess Plateau. Large-scale and long-term research on the effects of restoration projects on SMCs is needed to support more effective restoration policies. The interaction between afforestation and local environmental conditions, particularly water availability to plants, should be taken into account in afforestation campaigns in arid and semi-arid areas.

\section{Introduction}

Over the past century, afforestation and reforestation (artificial forestation) have been implemented extensively (Del Lungo et al., 2006), and increasing attention has been paid to their ecological impact. Artificial forestation was initially undertaken as an effective way to alleviate water loss and soil erosion, control desertification and conserve biodiversity (Lugo, 1997; Parrotta et al., 1997; Chirino et al., 2006; Barlow et al., 2007; Porto et al., 2009). It has recently gained attention as a potential mechanism for carbon sequestration (Wright et al., 2000; Fang et al., 2001; Pacala and Socolow, 2004; Marin-Spiotta et al., 2009). According to Fang (2001), the increase in biomass resulting from artificial forestation in China from the mid-1970s to 1998 has sequestered 0.45 petagrams of carbon. Today, reforestation and afforestation are acknowledged as effective ways to increase carbon storage in soil (Resh et al., 2002). Moreover, the decreases in bulk density and increases in soil organic matter (SOM), porosity and aggregation associated with tree planting (Kahle et al., 2005; Ilstedt et al., 2007; Li and Shao, 2006) can improve soil properties. In other cases, the rapid growth rates of

Published by Copernicus Publications on behalf of the European Geosciences Union. 
planted trees as compared to those of the native vegetation and the frequent removal of biomass can lead to a depletion of soil nutrients (Merino, 2004; Berthrong et al., 2009). However, one of the major issues that is currently of concern with respect to artificial forestation is the relationship between plantings and their effect on water resources.

The hydrological ramifications of artificial forestation have been studied extensively over the past two decades (Andreassian, 2004; Jobbagy and Jackson, 2004; Nosetto et al., 2005; Sahin and Hall, 1996; Van Dijk and Keenan, 2007). Several reviews have clearly detailed the close relationship between tree planting and runoff reduction (Brown et al., 2007, 2005; Bruijnzeel, 2004; Farley et al., 2005). This association may be very critical in arid and semi-arid areas (Farley et al., 2005), which are highly susceptible to land degradation (Puigdefàbregas and Mendizabal, 1998). In arid and semi-arid areas, tree planting has been widely adopted as a means of ecosystem restoration (Boix-Fayos et al., 2009; $\mathrm{Hu}$ et al., 2008). Given the close correlation between water yields and available water resources, most researchers in this field have focused on the effects of planted trees on water yields. However, changes in soil moisture after the planting of trees are of great significance for vegetation restoration and ecosystem sustainability in dry climate conditions (Schume et al., 2004; Wang et al., 2004b; Zhao and Li, 2005; Yang et al., 2010).

Planted trees affect the soil moisture content (SMC) through leaf interception of rainfall, root uptake of soil moisture, litter-layer buffering and changes in soil water-retention properties. Litter increases soil water retention by increasing the hydraulic conductivity of the duff layer (Robichaud, 2000). The physical and chemical properties of the soil (such as the SOM, bulk density, porosity and hydraulic conductivity) influence the transformation of precipitation into soil moisture and the soil water-retention capacity. These soil properties can be improved through natural and artificial re-vegetation (Ilstedt et al., 2007; Li and Shao, 2006), but artificial forestation can also decrease soil moisture due to the effects of leaf interception and root uptake. Gordon (1998) reviewed studies on Melaleuca and Sapium in Florida and found that high evapotranspiration rates can dry soil and drain wetlands. According to Chirino et al. (2001), 23-35\% of the total annual rainfall is intercepted by Pinus halepensis canopies in the Ventos-Agost catchment (Alicante, Spain).

Soil moisture can vary after the planting of trees under different conditions. According to previous studies, the effects of planted trees on topsoil moisture at depths of 0 $15 \mathrm{~cm}$ have been reported to be either significantly negative (Breshears et al., 1997), positive (Joffre and Rambal, 1998), negligible (Koechlin et al., 1986) or undetectable (Maestre et al., 2003). More recent studies have focused on shortterm local-scale variations (Breshears et al., 1997; Cao et al., 2006; Koechlin et al., 1986; Li et al., 2004; Maestre et al., 2003); however long-term regional-scale studies are rarely reported.
The Loess Plateau has a typical semi-arid climate and suffers from ecosystem degradation due to severe water loss and soil erosion (Chen et al., 2001). The Chinese government has aggressively invested in soil and water conservation and restoration programmes for the nation's ecosystems since the 1950s (Fu et al., 2002). Although extensive afforestation is currently taking place on the Loess Plateau, some negative effects of afforestation have been reported (McVicar et al., 2007; Yang et al., 2010). In some areas, afforestation has led to the emergence of a dry soil layer (Shangguan, 2007). Given the importance of the SMC to plants in arid and semiarid areas, a better understanding of the spatial distribution and after-planting variation in SMCs is crucial for the sustainability of a restored ecosystem. This research will also help direct ecosystem restoration in other arid and semi-arid areas of the world.

This study was designed to investigate the interaction between water resources (rainfall and soil moisture) and afforestation in the study area in order to support more effective restoration policies in arid and semi-arid areas. Optimal research methods should be based on regional, long-term monitoring of SMCs. However, this type of monitoring is timeconsuming and difficult. Instead, a regional, short-term study was conducted as an alternative. We examined the following: (1) the spatial distribution of SMCs on a regional scale; (2) the stand-structure variations of planted trees along the water gradient; and (3) the after-planting SMC variations with stand age and between watersheds.

\section{Methods}

\subsection{Study sites}

The study area is located on the Loess Plateau in the northern part of the Shaanxi Province $\left(35.16^{\circ} \mathrm{N}-37.86^{\circ} \mathrm{N}\right.$, $108.11^{\circ} \mathrm{E}-110.22^{\circ} \mathrm{E}$; $916-1586 \mathrm{~m}$ above sea level; Fig. 1). The area has a continental monsoon climate. Within the study area, the mean annual temperature (MAT) varies from 9.2-11.5 , and the mean annual precipitation (MAP) varies from 352-618 $\mathrm{mm}$. These statistics were calculated from 7yr-averaged temperature and precipitation records taken from 2000 to 2006 at 174 well-distributed climate stations on the Loess Plateau.

The most widely distributed soil type in the Loess Plateau is loess soil (Guo, 1992). The vegetation zone changes from temperate forest steppe in the southeast of the Loess Plateau to temperate steppe (Wu, 1980) in the northwest. Most of the native vegetation has been cleared in this region, and much of the land has been afforested. The most common tree species in the area are black locust (Robinia pseudoacacia L.), Chinese pine (Pinus tabulaeformis Carr.) and Korshinskii peashrub (Caragana korshinskii Kom.). R. pseudoacacia is an exotic nitrogen-fixing tree that is native to southeastern North America. It has been widely cultivated 


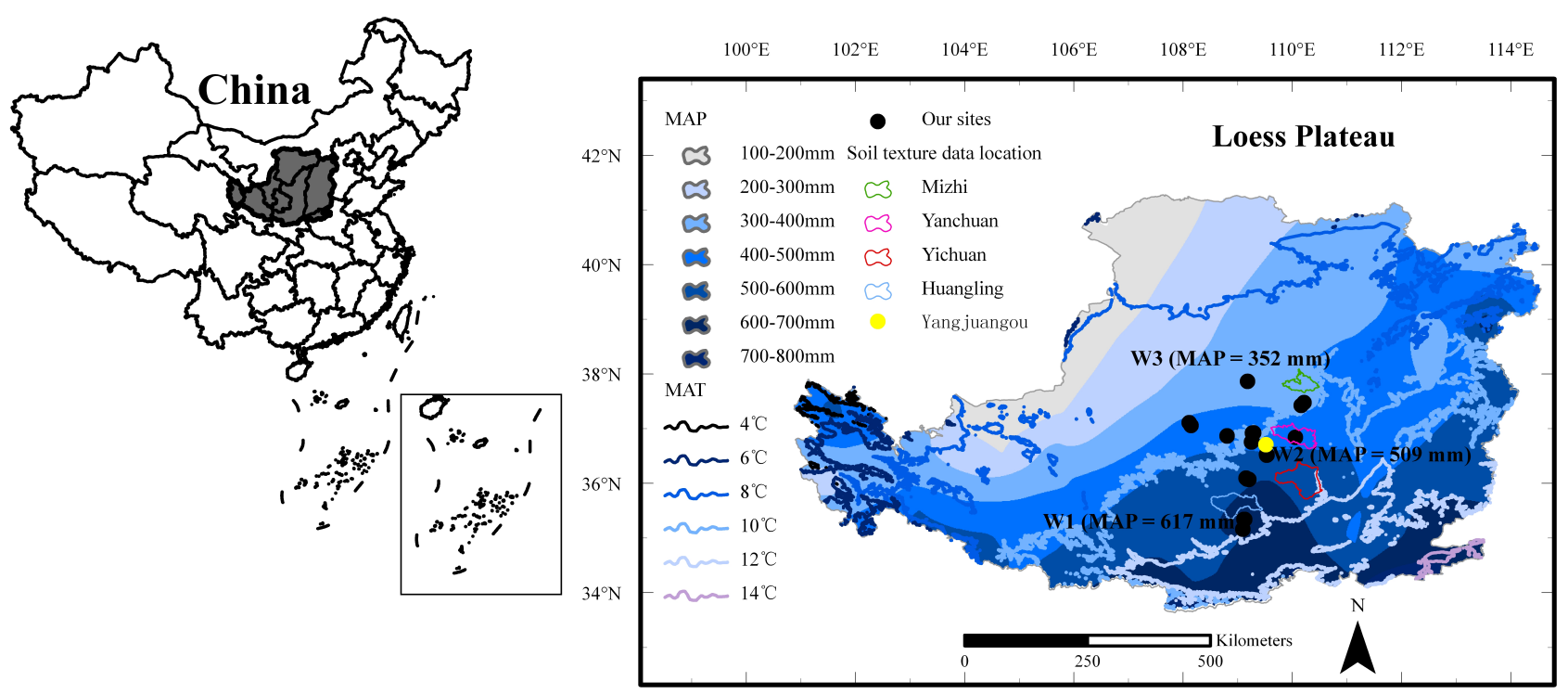

Fig. 1. Map of the study area on the Loess Plateau in central China and the distributions of the mean annual temperature (MAT) and mean annual precipitation (MAP). A total of 30 sites were selected. Sites W1, W2 and W3 are three watersheds located in the northern, middle and southern parts of the study area, respectively.

for restoration due to its drought resistance, high survival rate, ability to improve the soil-nutrient status and remarkable growth rate (Li et al., 1996; Shan et al., 2003). The most commonly used stand densities for afforestation in the study area are $5000(1 \times 2 \mathrm{~m})$ and $3333(1.5 \times 2 \mathrm{~m})$ plants $\mathrm{hm}^{-2}$, determined by interviewing local inhabitants. At the present time, $R$. pseudoacacia is the most widely cultivated species on the Loess Plateau.

The most important consideration for short-term regional research is to determine how to lessen the effect of individual rainfall events on SMC measurements. This will ensure that the data measured at different study sites are comparable. Undulating terrain and short, violent rainfall events on the Loess Plateau greatly reduce the impact of rainfall events on SMCs, particularly in upslope areas where afforestation has been applied. Historically, R. pseudoacacia saplings are usually planted in fish-scale pits. To minimise the effects of planting methods and slope variation (Querejeta et al., 2001), fish-scale pits in upslope areas were selected for planting. To further eliminate the influence of rainfall events on SMC measurements, the SMCs were measured at least five days after a rainfall event had occurred. To focus on the interaction between afforestation and SMC, the experiment was conducted during the growing season (late July through early August, 2008).

At the regional scale, 30 sites were selected, spanning a total area of $300 \mathrm{~km}$ by $190 \mathrm{~km}$ (Fig. 1). There is a wide range in annual precipitation between the study sites, from 352 to $617 \mathrm{~mm}$. In some watersheds, only one or two planting sites exist, so watershed analysis was impossible. Twelve sites in three watersheds (W1, W2 and W3) were selected for analysis of the after-planting SMC variation within different watersheds. As shown in Fig. 1, study site W1 is located at the southern boundary of the Loess Plateau and is located in the wettest and warmest area in the region, with a MAT of $11.0^{\circ}$ and a MAP of $617 \mathrm{~mm}$. The landscape at $\mathrm{W} 1$ is typical of plateau topography and is relatively flat as compared to the northern part of the Loess Plateau in Shaanxi Province. W2 is located in a typical loess hilly-gully region with a MAT of $10.4^{\circ}$ and a MAP of $509 \mathrm{~mm}$. W3 is located in the transitional zone between the desert area in the north and the Loess Plateau hilly-gully area in the south. It has the lowest MAT $\left(9.5^{\circ}\right)$ and MAP $(352 \mathrm{~mm})$ of the three sites.

\subsection{Sample collection and analysis}

The stand ages of the plantings were determined by interviewing local inhabitants. The latitude, longitude and elevation were determined for each study site using a Garmin GPS60 (Garmin International Inc., Olathe, KS, USA), while the site slope and aspect were determined using a compass. The slope aspect is positive and increases clockwise from $0^{\circ}$ to $360^{\circ}$ : a north-facing slope has an aspect of $0^{\circ}, 90^{\circ}$ is eastfacing, $180^{\circ}$ is south-facing and $270^{\circ}$ is west-facing. The aspect degree was further divided into four classes according to Qiu et al. (2001): (1) $135-225^{\circ}$, (2) $225-315^{\circ}$, (3) $45-$ $135^{\circ}$ and (4) $315-360^{\circ}$ and $0-45^{\circ}$. Grade 1 represents the slope aspect with the highest solar radiation reception, while Grade 4 has the lowest. To prepare for field measurements, a $10 \times 10 \mathrm{~m}$ quadrant was established at each study site, and three $2 \times 2 \mathrm{~m}$ sub-quadrants were chosen along a diagonal of each $10 \times 10 \mathrm{~m}$ quadrant. In each of the $10 \times 10 \mathrm{~m}$ quadrants, 
Table 1. Correlation analyses between depth-averaged SMC and spatial parameters $\left(N=30 ;{ }^{* *} P<0.01\right)$.

\begin{tabular}{lccccc}
\hline & $\begin{array}{c}\text { Latitude } \\
(\text { degree })\end{array}$ & $\begin{array}{c}\text { Longitude } \\
(\text { degree })\end{array}$ & $\begin{array}{c}\text { Elevation } \\
(\mathrm{m})\end{array}$ & $\begin{array}{c}\text { Slope } \\
(\text { degree })\end{array}$ & $\begin{array}{c}\text { Slope } \\
\text { aspect }\end{array}$ \\
\hline SMC $(0-100 \mathrm{~cm}, N=30)$ & $-0.806\left(^{* *}\right)$ & 0.149 & 0.171 & -0.322 & 0.224 \\
\hline
\end{tabular}
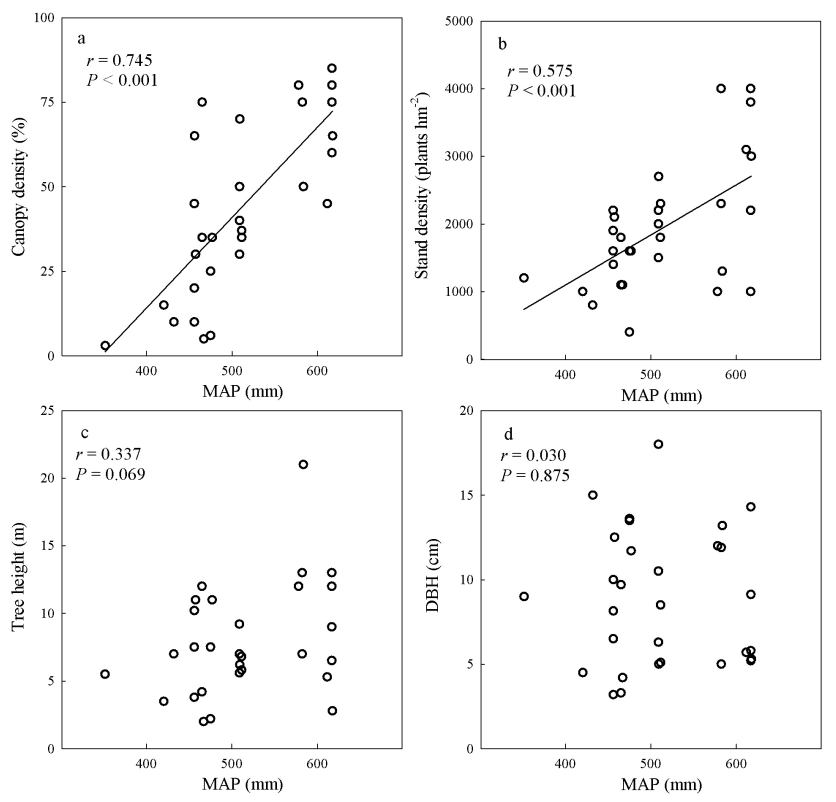

Fig. 2. Plots of canopy density, tree density, tree height and diameter at breast height $(\mathrm{DBH})$ variation with respect to the MAP.

the stand density (plants $\mathrm{hm}^{2}$ ), canopy density (the percentage of area covered by tree canopy) and the average tree diameter at breast height (DBH) were recorded. For each of the three $2 \times 2 \mathrm{~m}$ sub-quadrants, the percentage of herbaceous cover were recorded, and soil samples were collected to a depth of $100 \mathrm{~cm}$ at $10 \mathrm{~cm}$ intervals using a soil auger. SMCs were measured using the oven-drying method. Soil organic carbon (SOC, $\mathrm{mg} \mathrm{g}^{-1}$ ) was determined using the $\mathrm{K}_{2} \mathrm{Cr}_{2} \mathrm{O}_{7}$ titration method (Lu, 1999) for soils at depths of $0-10 \mathrm{~cm}$, $10-20 \mathrm{~cm}$ and $50-60 \mathrm{~cm}$, and the soil organic matter was derived as $1.7 \times$ SOC. All laboratory experiments were conducted at the Research Centre for Eco-Environmental Sciences, Chinese Academy of Science.

\subsection{Statistical analysis}

The data in this study were analysed on two different scales. At the regional scale, the data from all 30 sites were combined. Bivariate correlation analysis was used to determine the variation of SMC with latitude, longitude, elevation, slope and slope aspect, and it was also used to identify standstructure variations with the MAP and the relationship be- tween SMCs at different depths and stand ages (from 5 to 45 yr).

At the watershed scale, the data for $\mathrm{W} 1, \mathrm{~W} 2$ and $\mathrm{W} 3$ were used. Descriptive statistics were used to give the mean and standard deviation of SMCs at different depths for each site. A comparison of plantings with different stand ages in the same watershed and of the watershed-averaged SMCs of the three watersheds was performed using one-way ANOVA, and post-hoc multiple comparisons were made using the least significant difference (LSD). The relationship between the SMC and SOM in different watersheds was determined by bivariate correlation analysis. The following logarithmic regression was used to test the effect of self-thinning in different watersheds:

$\log w=\log k+\operatorname{alog} N$

where $w$ is the plant size, with $\mathrm{DBH}(\mathrm{cm})$ as an indicator of plant size; $k$ is a species-specific constant that has an interspecific range; $a$ is a constant that is generally thought to lie between -1.3 and -1.8 and has an ideal value of -1.5 (Adler, 1997); $N$ is the stand density (plants $\mathrm{hm}^{-2}$ ).

All statistical analyses were performed with the statistical software package SPSS 16.0 (SPSS Inc., Chicago, Illinois, USA).

\section{Results}

\subsection{Spatial distribution of depth-averaged SMCs}

The depth-averaged SMC varied widely at the regional scale. It decreased from $18 \%$ to $3 \%$ from the south to the north of the study area. As shown in Table 1 , it decreased significantly with increasing latitude, with a high correlation coefficient. No significant relationships were found between the SMC and longitude, elevation, slope, or slope aspect.

\subsection{Variation in R. pseudoacacia stand-structure}

\subsubsection{Regional scale}

The canopy density and stand density decreased significantly with decreasing MAP (Fig. 2a, b). The tree height and MAP exhibited a weaker relationship, which was not statistically significant at the 0.05 level $(P=0.069)$ (Fig. 2c). The DBH and MAP exhibited the weakest relationship (Fig. 2d). 
Table 2. Correlation analyses between SMCs measured at different depths and stand ages on the regional scale (correlation coefficients and $P$ values).

\begin{tabular}{lrrrrrrrrrrr}
\hline & & & & & & & & Depth- \\
Soil depth (cm) & $0-10$ & $10-20$ & $20-30$ & $30-40$ & $40-50$ & $50-60$ & $60-70$ & $70-80$ & $80-90$ & $90-100$ & averaged \\
\hline$N=30$ & -0.201 & -0.348 & -0.406 & -0.399 & -0.398 & -0.364 & -0.358 & -0.353 & -0.355 & -0.350 & -0.384 \\
& $(0.286)$ & $(0.059)$ & $(0.026)$ & $(0.029)$ & $(0.029)$ & $(0.048)$ & $(0.052)$ & $(0.056)$ & $(0.054)$ & $(0.058)$ & $(0.036)$ \\
$N=29$ & -0.174 & -0.276 & -0.351 & -0.354 & -0.351 & -0.310 & -0.300 & -0.290 & -0.288 & -0.319 & -0.327 \\
Values after & $(0.367)$ & $(0.148)$ & $(0.062)$ & $(0.059)$ & $(0.062)$ & $(0.102)$ & $(0.114)$ & $(0.127)$ & $(0.129)$ & $(0.092)$ & $(0.083)$ \\
elimination of & & & & & & & & & & & \\
45-year-old site) & & & & & & & & & & \\
\hline
\end{tabular}

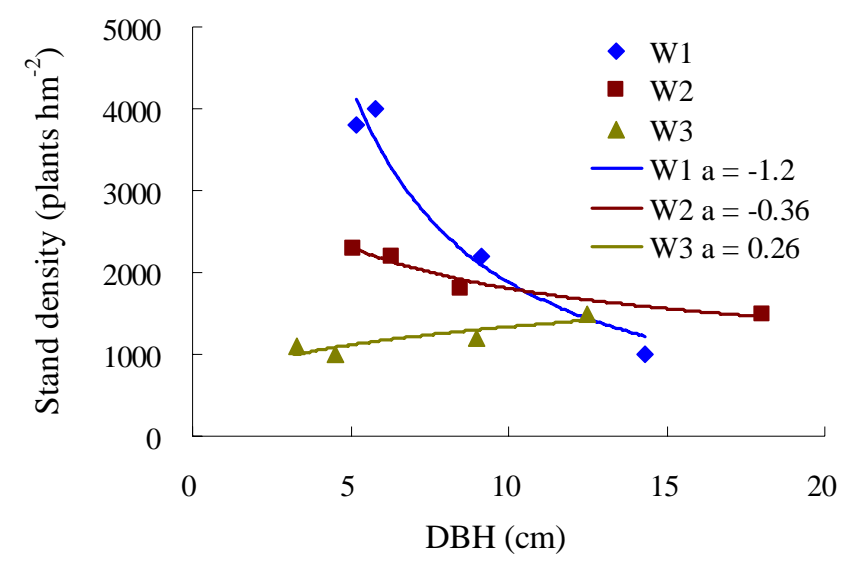

Fig. 3. Logarithmic regression between plant size and density.

\subsubsection{Comparisons between watersheds}

From the logarithmic regression between DBH and stand density (equation 1, Fig. 4), the regression constant a values determined for sites $\mathrm{W} 1, \mathrm{~W} 2$ and $\mathrm{W} 3$ were $-1.20,-0.36$ and 0.26 , respectively. The regression constant a value of W1 was similar to the determined a value for self-thinning ( -1.3 to -1.8 , Fig. 3) (Adler, 1997).

In W1, the stand densities in the 5- and 10-year-old plantings were high, and the stand density decreased with increasing stand age. In W2, this trend lessened, while in W3, no trend was found (Fig. 4a). From W1 to W2, the canopy density decreased gradually. In W1, the canopy density was constant and high, while in W2 and W3, the canopy density was constant and low (Fig. 4b).

\subsection{Soil moisture variation with stand age}

\subsubsection{Regional scale}

The depth-averaged SMC had a significant negative correlation with stand age at the regional scale. However, the relationship between stand age and SMC was only significant at depths of $20-60 \mathrm{~cm}$. At depths of $0-20 \mathrm{~cm}$ and $60-100 \mathrm{~cm}$, there was no correlation (Table 2).

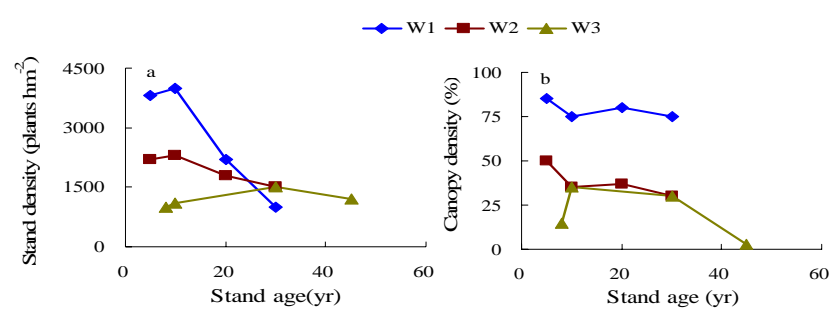

Fig. 4. Variations in stand density and canopy density with stand age in the different watersheds.

With a MAP of only $352 \mathrm{~mm}$, W3 was the driest watershed and was also the only one in which 45 -year-old plantings were present. To eliminate any bias, the relationship between stand age and SMC was further examined after excluding the 45-year-old site (Table 2). The SMC still had a negative correlation with stand age at the regional scale. Although no significant relationships were found, the absolute values of the correlation coefficients between SMCs at depths of $20-50 \mathrm{~cm}$ were higher as compared to the other depths, and the $P$ values determined for depths of $20-50 \mathrm{~cm}$ were close to 0.05 .

\subsubsection{Comparisons between watersheds}

\section{SMCs in different watersheds}

Large differences in SMC profiles were evident between the three watershed sites: W1, W2 and W3. The average SMC of W1 (Fig. 5a) was the highest of the three watersheds because it had the highest amount of precipitation (MAP $=617 \mathrm{~mm}$ ). In the soil profile for W1, the SMC decreased slightly with depth $(0-100 \mathrm{~cm})$. The 30 -year-old tree sites maintained a significantly higher SMC than the sites with younger trees.

In W2 (Fig. 5b; MAP = 509 mm), two distinct SMC layers were evident in the soil profile. In the top layer $(0-40 \mathrm{~cm})$, the SMC decreased rapidly with depth. In the lower layer $(40-100 \mathrm{~cm})$, the SMC was relatively constant with depth, with the exception of locations in which the youngest (5- 


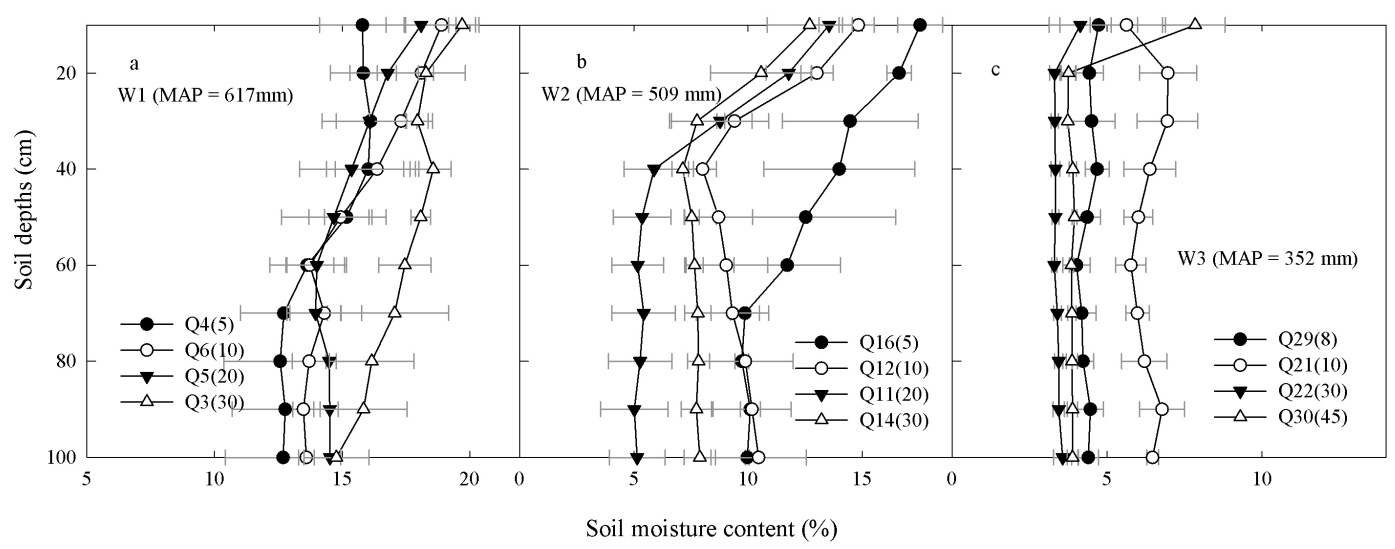

Fig. 5. Soil moisture profiles for watersheds (a) W1, (b) W2 and (c) W3. The bars indicate the standard deviations of the means $(N=3)$. In the legends, the numbers in the parentheses after W1, W2 and W3 indicate stand ages.

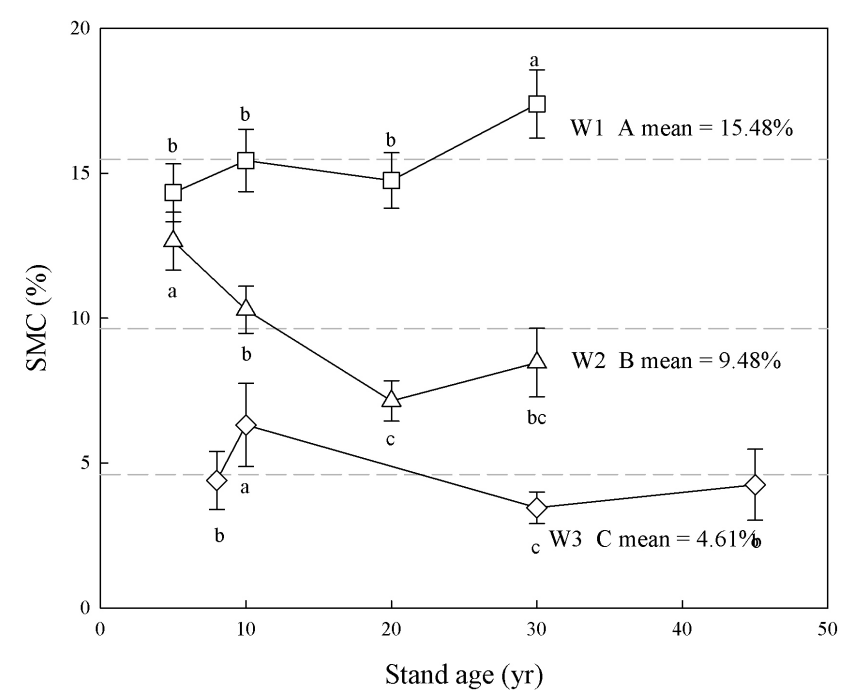

Fig. 6. SMC versus stand age for the different watersheds. The bars indicate the standard deviations of the means. Lowercase letters indicate differences between depth-averaged SMCs with different stand ages for a given watershed, significant at the 0.05 level. Uppercase letters after $\mathrm{W} 1, \mathrm{~W} 2$ and $\mathrm{W} 3$ indicate differences between watershed-averaged SMCs significant at the 0.05 level.

year-old) trees were present. At these locations, the SMCs decreased gradually along the top $70 \mathrm{~cm}$ of the profile.

In the driest watershed, W3 (Fig. 5c), the SMC was low $(\mathrm{MAP}=352 \mathrm{~mm})$. In the 8-, 30- and 45-year-old stands, the SMC was less than $5 \%$ and varied minimally across the entire soil profile (except for the SMC at the soil surface in the 45-year-old stand, which maintained a relatively high value of approximately $7.8 \%$ ). The SMC in the 10-year-old stand was slightly higher (a depth-averaged value of approximately $6 \%$ ) and varied minimally with depth.
As shown in Fig. 6, the SMCs were the highest in W1 and the lowest in W3. This corresponds to the precipitation distribution. The SMCs, however, also varied with stand age. In W1, the SMC levels were high (approximately $15 \%$ ) for stands younger than $20 \mathrm{yr}$, but they were significantly higher (approximately $17 \%$ ) for 30-year-old stands. The SMC decreased significantly from $12.7 \%$ to $10.3 \%$ to $7.1 \%$ in W2 with corresponding increases in stand age from 5 to 10 to 20 yr. The SMC increased slightly from $7.1 \%$ to $8.5 \%$ as the stand age increased from 20 to $30 \mathrm{yr}$; however, the difference in SMC was smaller than the difference between 10- and 20year-old stands. In W3, the SMC levels were considerably lower (4-6\%) and did not appear to change with stand age. The watershed-averaged SMC value of $4.6 \%$ is similar to the permanent wilting point of the soil (Li et al., 1996; Wang et al., 2004b).

\section{The relationship between SMC and SOM}

The correlations between the SMC and SOM (0-10, 10-20 and $50-60 \mathrm{~cm}$ depth) for the different watersheds are given in Fig. 7. The SMC and SOM show a significantly positive relationship for $\mathrm{W} 1$ (Fig. 7a), while no significant relationship was found for W2 or W3 (Fig. 7b, c). When the data point with the highest SOM was removed from the W2 data set (this point is thought to reflect a saturation response of the SMC when the SOM content is greater than approximately $25 \mathrm{mg}$ per gram of soil), the SMC and SOM were significantly correlated $(r=0.735, P=0.01)$. This relationship, however, was derived from variations of these two factors with soil depth (SMC: $r=-0.775, P<0.01$; SOM: $r=-0.914, P<0.01)$. When depth was used as a control factor, the partial correlation coefficient between the SMC and SOM was $0.102(P=0.779)$. In comparison, the partial correlation coefficient between the SMC and SOM in W1 was $0.786(P<0.01)$, which reflects the effect of the SOM on SMC in $\mathrm{W} 1$. 

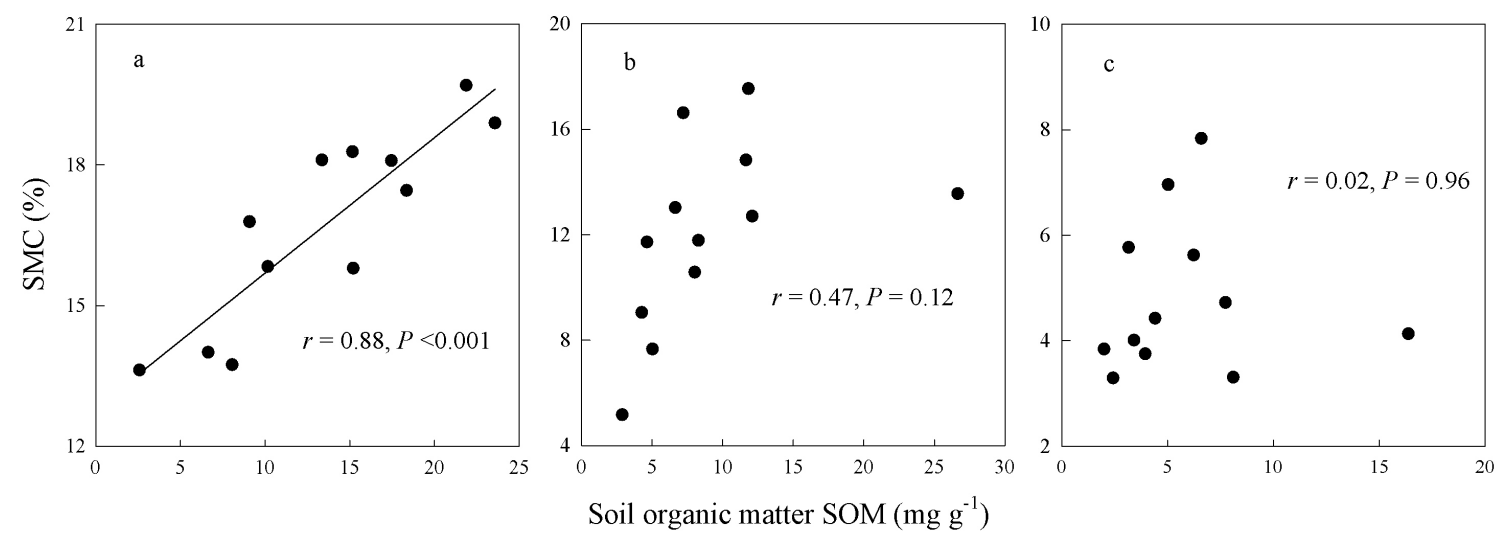

Fig. 7. Correlations between the SMC (soil moisture content) and SOM (soil organic matter) in watersheds (a) W1, (b) W2 and (c) W3.

In watershed $\mathrm{W} 1$, the topsoil organic matter content was highly correlated with increasing stand age $(0-$ to $10-\mathrm{cm}$ depth: $r=0.49, P<0.01 ; 10$ - to 20-cm depth: $r=0.551$, $P<0.01)$.

\section{Discussion}

\subsection{Spatial distribution of SMCs}

The SMC is the most important source of water used directly by plants and should be a primary consideration in the afforestation of arid and semi-arid areas. Given the wide range of afforestation programmes in the Loess Plateau, research on the spatial distribution of the SMC is necessary in this region. Most research on the Loess Plateau has been restricted to the watershed scale, but some factors may influence the SMC at other scales. The decisive role that MAP levels have played in determining SMCs at the regional scale on the Loess Plateau is not surprising. Due to the deep groundwater levels, precipitation is the only source of soil moisture, which strengthens the relationship between the SMC and MAP. An upslope position can lessen the effect of the terrain on the SMC because the effect of runoff is eliminated and the shade effect from undulating terrain is also lessened. In this study, the slope and aspect shape exert insignificant effects on the SMC at the regional scale. As with latitude and longitude, elevation was found to not directly affect the SMC, but to indirectly affect the SMC via other factors (e.g., temperature and precipitation). In this study, the MAP and MAT did not have significant relationships with elevation (MAP: $r=0.054, P=0.778$; MAT: $r=0.277, P=0.138$ ). Therefore, no significant relationship was found between altitude and SMC. Due to the homogeneous texture of the soils in the Loess Plateau (refer to Supplement Figs. 1 and 2 for soil texture data at the regional and watershed scales and Fig. 1 for the locations relating to soil texture data), soil properties are unlikely to be dominant factors for determining SMCs at the regional scale. Based on the above analysis, the MAP can be used as a major factor to determine the spatial distribution of SMCs, which may be used along with vegetation species to the divide the Loess Plateau into different ecological regions.

\subsection{Stand-structure variations of R. pseudoacacia populations along the rainfall gradient}

Rampike and dwarf forms of $R$. pseudoacacia were frequently found in the northern area of the study site. The emergence of rampike and dwarf trees was reflected through a trend of decreasing stand density and tree height with decreasing MAP (Fig. 2). The results from this study suggest that afforestation measures should be regulated according to the environmental gradient in which they are implemented. However, unified measures are often adopted for a variety of areas. For example, the stand densities most commonly used in afforestation of the Loess Plateau are $5000(1 \times 2 \mathrm{~m})$ and $3333(1.5 \times 2 \mathrm{~m})$ plants $\mathrm{hm}^{-2}$. However, a density of less than 1000 plants hm ${ }^{-2}$ has been found to be appropriate under different MAP levels, which is far less than the initial adopted stand density (Table 3). In watershed W1, a high MAP led to a high tree survival rate, but subsequent growth made competition within the stand population more intense. As shown in Fig. 3, the regression constant a value determined for W1 $(-1.20)$ was found to be very similar to the regression constant a value for self-thinning $(-1.3$ to -1.8$)$ (Adler, 1997). In addition, the constant high canopy density resulted in space and resource competition among individual trees in W1 (Fig. 4a). However, the high stand densities in young stands and the decreasing trend of stand density with stand age (Fig. 4b) imply a density-dependent mortality. Therefore, the self-thinning observed in watershed W1 was probably an important process accompanying afforestation. In W2 and W3, the stand densities and canopy densities were low, and drought led to a high mortality of planted saplings. Drought, as opposed to self-thinning, was found to be the main factor affecting mortality rates in $\mathrm{W} 2$ and $\mathrm{W} 3$. 
Table 3. Appropriate stand density for the Loess Plateau.

\begin{tabular}{crrlll}
\hline MAP (mm) & $\begin{array}{r}\text { Appropriate } \\
\text { stand density } \\
\left(\text { plants hm }{ }^{-2}\right)\end{array}$ & $\begin{array}{r}\text { Stand age } \\
(\mathrm{yr})\end{array}$ & $\begin{array}{l}\text { Criterion for } \\
\text { judging } \\
\text { appropriation }\end{array}$ & Method & Literature \\
\hline 576 & $1500-3000$ & 45 & No soil desiccation & WinEPIC model & Li et al. (2008b) \\
576 & 2000 & 11 & Maximum forest biomass & Measured data and logistic model & Sun et al. (2006) \\
576 & 876 & 13 & Low water stress for plants & Measured data and water balance model & Wu et al. (2007) \\
535 & 1500 & 45 & No soil desiccation & WinEPIC model & Li et al. (2008b) \\
487 & 833 & 18 & Maximum forest biomass & Measured data and power function model & Wang et al. (2005) \\
416 & $<833$ & 11 and 18 & Maximum forest biomass & Measured data and regression model & Yin et al. ( 2008) \\
\hline
\end{tabular}

\subsection{The cumulative effects of afforestation on SMCs}

\subsubsection{The effect of the R. pseudoacacia root system on SMCs}

R. pseudoacacia is a shallow-rooted species. Although the greatest vertical root depths vary from $190 \mathrm{~cm}$ (Wang et al., 2004a) to $120 \mathrm{~cm}$ (Liu et al., 2007) in the Loess Plateau, the effective roots are concentrated at a depth of $0-60 \mathrm{~cm}$ and at a depth of 20-60 cm in particular (Cao et al., 2006; Liu et al., 2007; Wang et al., 2004a). This implies that this species will largely absorb soil moisture at a depth of $20-60 \mathrm{~cm}$. Although no statistically significant relationships were found after eliminating the 45-year-old site data for W3, the negative correlations between the SMC and stand age at the 20to 50-cm depth were stronger than those at other depths at the regional scale after the exclusion of the 45 -year-old site. However, the intensity and nature of the relationship between the SMC and stand age may be affected by other environmental factors, and the relationship between the SMC and stand age differed between watersheds.

\subsubsection{After-planting SMC variation in different watersheds}

\section{Watershed W1}

W1 $(\mathrm{MAP}=617 \mathrm{~mm}$ ) had a higher SMC than the other watersheds. The consistently high SMC levels demonstrated good water supplementation across the soil profile (Fig. 5a). A previous study has also shown that the SMC in the growing season in this region is effectively maintained by natural rainfall (Li, 1983). The watershed-averaged SMC in this study, $15.48 \%$, is roughly equivalent to the average waterholding capacity previously found for the soil $(15.00 \%$; $\mathrm{Li}$ et al., 2008a). Under such conditions, the effect of tree root uptake on the SMC is lessened by intermittent supplementation from precipitation, and the SMC largely depends on the soil water-holding capacity. Joffre (1988) revealed that the soil water content in woodland sites in southern Spain
(MAP $=650 \mathrm{~mm}$ ) is greater than that in grass sites due to improvements in soil permeability and water-holding capacity after the planting of trees.

Soil water-holding capacity and water-retention ability are mainly related to SOM, soil texture, porosity and bulk density (Husein Malkawi et al., 1999). The soil texture in the Loess Plateau is derived from parent materials, and the soil is relatively uniform in space and over time ( $\mathrm{Li}$ and Shao, 2006). SOM promotes the formation of soil aggregates by binding soil particles together, increasing soil porosity and, thus, improving soil structure and decreasing bulk density (Husein Malkawi et al., 1999; Langdale et al., 1992; Li and Shao, 2006; Soane, 1990; Watts and Dexter, 1997). Therefore, SOM is a good indicator of soil water-holding capacity and soil water-retention ability (Franzluebbers, 2002; Li and Shao, 2006).

In watershed $\mathrm{W} 1$, the topsoil organic matter content increased significantly with increasing stand age, consistent with the results of Paul et al. (2002). The SMC was found to have a significantly positive correlation with SOM (Fig. 7a). Therefore, it is expected that the soil moisture status should improve with stand age in W1. In watersheds W2 and W3 (Fig. 7b, c), the insignificant relationship between the SMC and SOM indicates a weaker effect of the soil water-holding capacity on the SMC.

\section{Watershed W2}

In W2, precipitation and root uptake may play an important role in determining the SMC. Precipitation was found to wet only the upper soil layer (Fig. 5b). Water use by planted species (especially those selected for rapid growth) initially increases quickly and then gradually decreases with age (Almeida et al., 2007; Farley et al., 2005). For Eucalyptus sieberi, a transpiration peak is reached when stands reach $15 \mathrm{yr}$ of age (Roberts et al., 2001; Vertessy et al., 2001). In the early stages of planting growth, afforestation has been found to dry the soil quickly, as evidenced by increasing water use in plantings. From the results shown in Fig. 6, it can 
be hypothesised that the peak water usage for R. pseudoacacia in this area occurs when stands reach between 20 and 30 $\mathrm{yr}$ of age. The decreased water usage of older trees might be another cause of the higher SMC at the 30-year-old tree site in W1. In comparison with $\mathrm{W} 1$, the effects of precipitation and root uptake on the SMC in W2 were distinct. Limited precipitation and concentrated root uptake at the 20- to 60$\mathrm{cm}$ depth shaped the SMC of the soil profile in this watershed.

\section{Watershed W3}

In watershed W3 (Fig. 5c), the observed soil profile distribution of the SMC indicates the long-term absence of a water supply. In the 8-, 30- and 45-year-old stands, the SMCs nearly reached the species' wilting point (Li et al., 1996; Meng et al., 2008), indicating that water was not consistently available to the trees. In the 10-year-old stand, the SMC was slightly higher than the wilting point, and water could have been partially used by trees. This finding is supported by a slight decrease in SMC at the depth of $20-60 \mathrm{~cm}$. No obvious trend was found between the SMC and stand age. Divergences in the SMCs of the different stands are likely to have come from differences in terrain (slope, aspect and slope position) given the uniform soil texture in this area. All four stands were located in upslope areas, and the SMC levels exhibited no significant trend with slope. Comparatively, the relationship between the SMC and aspect was clearer. The graded slope aspects of the 8-, 10-, 30- and 45-year-old stands were 3, 4, 1 and 3, respectively. The SMC was found to increase with decreasing solar radiation. In watershed W3, the slope aspect, which has a significant effect on solar radiation reception on slopes, also had an important effect on the SMC.

\subsubsection{Implication for restoration activities in arid and semi-arid areas}

As stated in Sect. 4.3.2, the after-planting SMC variations were largely dependent on the local rainfall. Therefore, a single standard is not appropriate for ecosystem restoration. In arid and semi-arid areas, water resources should be the central consideration of afforestation. Afforestation may only be practical when there is sufficient precipitation (e.g., MAP $>617 \mathrm{~mm}$ on the Loess Plateau). Trees planted in some areas with water shortages might be able to grow well during the initial stage (e.g., MAP $=509 \mathrm{~mm}$ on the Loess Plateau); however large water uptakes by the plantings will dry the soil and lead to an unsustainable ecosystem. In extremely dry areas (e.g., MAP $<352 \mathrm{~mm}$ on the Loess Plateau), insufficient SMCs often fail to support the growth of the plantings.

\subsection{The trend of soil drying after tree planting and the potential effect on vegetation succession}

A trend of after-planting soil drying was only found for $\mathrm{W} 2$, and this trend will recover gradually with planting age (Fig. 6). This trend was not found in watersheds with higher (W1) or lower (W3) MAPs. In W2, the initial drying trend may exert a negative effect on vegetation renewal and the associated ecosystem. The growth of afforested trees was limited by this drying trend, and many "dwarf" trees were found (Han and Hou, 1996; Hou and Huang, 1991). Furthermore, the undergrowth vegetation succession may be altered by this drying trend. Species that are adaptable to dry environments and have shallow roots can quickly become dominant (Francis and Parrotta, 2006; Li et al., 2004).

On the Loess Plateau, afforestation may exert the biggest impact on the SMC of sites with mid-range MAPs (e.g., $\mathrm{W} 2 \mathrm{MAP}=509 \mathrm{~mm}$ ). In this area, afforestation may lead to drought stress for the planted trees and deplete soil moisture, which is critical to vegetation restoration. Tree adaptability and the ecological significance of establishing plantings should be comprehensively considered in the afforestation process.

\section{Conclusions}

Afforestation is one of the most important restoration measures for arid and semi-arid ecosystems. However, it is largely limited by water availability in these ecosystems. The soil moisture content (SMC) is the most important water resource available to plants when grown in locations where groundwater tables are deep. The success of ecosystem restoration is largely dependent on the spatial and temporal variation of the SMC at the regional scale.

This study suggests that the mean annual precipitation (MAP) can be used to determine the SMC in the northern region of the Loess Plateau. Therefore, it can also be used as an index to define different ecological regions in the study area. In areas where the MAP was less than $400 \mathrm{~mm}$ (W3), the SMC was found to be near the wilting point $(\mathrm{SMC}=5 \%)$. Over-planting in such areas will not only lead to a waste of money and human power invested in afforestation restoration projects, but will also hamper the restoration of degraded ecosystems. The planting of fast-growing species may dry soils in areas with moderate MAPs (e.g., W2 $\mathrm{MAP}=509 \mathrm{~mm}$ ) in the initial stages. Less water-demanding species would be more suitable for ensuring the success of afforestation projects. In areas where the MAP is relatively high (e.g., W1 MAP $=618 \mathrm{~mm}$ ), the SMC was found to approach the average water-holding capacity of the soil. The SMC in such areas is high enough to maintain the growth of planted trees during the growing season. plantings located in these areas are likely to improve the SMC due to the high 
water-holding capacity of the soils and will therefore promote the natural recovery of these areas.

The results from this study show that local environmental conditions, particularly water availability for plants, should been taken into account in the establishment of artificial plantings in arid and semi-arid areas. Further regional-scale and long-term research on the effects of restoration projects on SMCs is needed to ensure that more effective restoration policies are implemented.

\section{Supplementary material related to this article is available online at: http://www.hydrol-earth-syst-sci.net/15/2519/2011/ hess-15-2519-2011-supplement.pdf.}

Acknowledgements. We acknowledge the considerable assistance of Lei Yang and Xiao-Hui Ding with sampling and laboratory procedures. This research was supported by the National Basic Research Programme of China (No. 2009CB421104), the National Natural Science Foundation of China (No. 40930528 and 40871085), and the CAS/SAFEA International Partnership Programme for Creative Research Teams of "Ecosystem Processes and Services."

Edited by: Y. Fan

\section{References}

Adler, F. R.: A model of self-thinning through local competition, Proc. Natl. Acad. Sci. USA, 93, 9980-9984, 1996.

Almeida, A. C., Soares, J. V., Landsberg, J. J., and Rezende, G. D.: Growth and water balance of Eucalyptus grandis hybrid plantations in Brazil during a rotation for pulp production, Forest Ecol. Manag., 251, 10-21, 2007.

Alvarez, V. M., Baille, A., Martínez, J. M. M., and González-Real, M. M.: Efficiency of shading materials in reducing evaporation from free water surfaces, Agr. Water Manage., 84, 229-239, 2006.

Andreassian, V.: Waters and forests: from historical controversy to scientific debate, J. Hydrol., 291, 1-27, 2004.

Barlow, J., Mestre, L. A. M., Gardner, T. A., and Peres,C. A.: The value of primary, secondary and plantation forests for Amazonian birds, Biol. Conserv., 136, 212-231, 2007.

Berthrong, S. T., Jobbagy, E. G., and Jackson, R. B.: A global metaanalysis of soil exchangeable cations, $\mathrm{pH}$, carbon, and nitrogen with afforestation, Ecol. Appl., 19, 2228-2241, 2009.

Boix-Fayos, C., De Vente, J., Albaladejo, J., and Martinez-Mena, M.: Soil carbon erosion and stock as affected by land use changes at the catchment scale in Mediterranean ecosystems, Agr. Ecosyst. Environ., 133, 75-85, 2009.

Breshears, D. D., Myers, O. B., Johnson, S. R., Meyer, C. W., and Martens, S. N.: Differential use of spatially heterogeneous soil moisture by two semiarid woody species: Pinus edulis and Juniperus monosperma, J. Ecol., 85, 289-299, 1997.

Brown, A. E., Zhang, L., McMahon, T. A., Western, A. W., and Vertessy, R. A.: A review of paired catchment studies for deter- mining changes in water yield resulting from alterations in vegetation, J. Hydrol., 310, 28-61, 2005.

Brown, A. E., Podger, G. M., Davidson, A. J., Dowling, T. I., and Zhang, L.: Predicting the impact of plantation forestry on water users at local and regional scales - An example for the Murrumbidgee River Basin, Australia, Forest Ecol. Manag., 251, 8293, 2007.

Bruijnzeel, L. A.: Hydrological functions of tropical forests: not seeing the soil for the trees?, Agr. Ecosyst. Environ., 104, 185228, 2004.

Cao, Y., Zhao, Z., Qu, M., Cheng, X. R., and Wang, H. D.: Effects of Robinia pseudoacacia roots on deep soil moisture status, Chin. J. Appl. Ecol., 17, 765-768, 2006 (in Chinese).

Chen, L. D., Wang, J., Fu, B. J., and Qiu, Y.: Land-use change in a small catchment of northern Loess Plateau, China, Agr. Ecosyst. Environ., 86, 163-172, 2001.

Chirino, E., Sánchez, J. R., Bonet, A., and Bellot, J.: Effects of afforestation and vegetation dynamics on soil erosion in a semiarid environment (SE Spain), in: Ecosystems and Sustainable Development III, Alicante, Spain, 6-8 June, 2001, 239-248, 2001.

Chirino, E., Bonet, A., Bellot, J., and Sanchez, J. R.: Effects of 30-year-old Aleppo pine plantations on runoff, soil erosion, and plant diversity in a semi-arid landscape in south eastern Spain, Catena, 65, 19-29, 2006.

Fang, J. Y., Chen, A. P., Peng, C. H., Zhao, S. Q., and Ci, L.: Changes in forest biomass carbon storage in China between 1949 and 1998, Science, 292, 2320-2322, 2001.

Del Lungo, A., Ball, J., and Carle, J.: Global planted forests thematic study: results and analysis, in: Planted Forests and Trees Working Paper 38, Food and Agriculture Organization of the United Nations, Rome, Italy, 38-42, 2006.

Farley, K. A., Jobbagy, E. G., and Jackson, R. B.: Effects of afforestation on water yield: a global synthesis with implications for policy, Global Change Biol., 11, 1565-1576, 2005.

Guo, Z. Y., Huang, A. L., Feng, L. X., Fan S. Q., and Wang, H. J. (Eds.): Shaanxi Soil, Science Press, Beijing, China, 1992 (in Chinese).

Francis, J. K. and Parrotta, J. A.: Vegetation response to grazing and planting of Leucaena leucocephala in a Urochloa maximumdominated grassland in Puerto Rico, Caribb. J. Sci., 42, 67-74, 2006.

Franzluebbers, A. J.: Water infiltration and soil structure related to organic matter and its stratification with depth, Soil Till. Res., 66, 197-205, 2002.

Fu, B. J., Chen, L. D., Qiu, Y., and Wang, J. (Eds.): Land Use Structure and Ecological Processes in the Loess Hilly Area, China, Commercial Press, Beijing, China, 2002 (in Chinese).

Gordon, D. R.: Effects of invasive, non-indigenous plant species on ecosystem processes: lessons from Florida, Ecol. Appl., 8, 975-989, 1998.

Han, R. L. and Hou, Q. C.: An analysis of Genesis of small aged trees on the Loess Plateau, Agric. Res. Arid Areas, 14, 104-108, 1996 (in Chinese).

Hou, Q. C. and Huang, X.: Study on the forming of 'small olded tree' and the transforming way in the Loess Plateau, J. Soil Water Conserv., 5, 64-72, 1991 (in Chinese).

Hu, Y. L., Zeng, D. H., Fan, Z. P., Chen, G. S., Zhao, Q., and Pepper, D.: Changes in ecosystem carbon stocks following grassland 
afforestation of semiarid sandy soil in the southeastern Keerqin Sandy Lands, China, J. Arid Environ., 72, 2193-2200, 2008.

Husein Malkawi, A. I., Alawneh, A. S., and Abu-Safaqah, O. T.: Effects of organic matter on the physical and the physicochemical properties of an illitic soil, Appl. Clay Sci., 14, 257-278, 1999.

Ilstedt, U., Malmer, A., Elke, V., and Murdiyarso, D.: The effect of afforestation on water infiltration in the tropics: A systematic review and meta-analysis, Forest Ecol. Manag., 251, 45-51, 2007.

Joffre, R. and Rambal, S.: Soil-water improvement by trees in the rangelands of southern Spain, Acta Oecol.-Oec. Plant., 9, 405422, 1998.

Jobbagy, E. G. and Jackson, R. B.: Groundwater use and salinization with grassland afforestation, Global Change Biol., 10, 1299 1312,2004

Kahle, P., Baum, C., and Boelcke, B.: Effect of afforestation on soil properties and mycorrhizal formation, Pedosphere, 15, 754-760, 2005.

Koechlin, B., Rambal, S., and Debussche, M.: Effects of pioneer trees on soil moisture content in Mediterranean old fields, Acta Oecol., 7, 177-190, 1986.

Langdale, G. W., West, L. T., Bruce, R. R., Miller, W. P., and Thomas, A. W.: Restoration of eroded soil with conservation tillage, Soil Technol., 5, 81-90, 1992.

Li, H. J., Wang, M. B., Chen, L. F., and Cai, B. F.: Study on hydrologic ecology of Robinia pseudoacacia population in northwestern Shanxi, Acta Phytoecologica Sin., 20, 151-158, 1996 (in Chinese).

Li, J., Chen, B., Li, X. F., Zhao, Y. J., Ciren, Y. J., Jiang, B., Hu, W., Cheng, J. M., and Shao, M. A.: Effects of deep soil desiccation on artificial forestlands in diferent vegetation zones on the Loess Plateau of China, Acta Ecol. Sin., 28, 1429-1445, 2008a (in Chinese).

Li, J., Wang, X. C., Shao, M. A., Zhao, Y. J., and Li, X. F.: Simulation of water productivity and soil desiccation efects of diferent planting density black locust forestlands on the Loess Plateau, Acta Ecol. Sin., 28, 3125-3142, 2008b (in Chinese).

Li, X. R., Ma, F. Y., Xiao, H. L., Wang, X. P., and Kim, K. C.: Long-term effects of revegetation on soil water content of sand dunes in arid region of northern China, J. Arid Environ., 57, 116, 2004.

Li, Y. Y. and Shao, M.A.: Change of soil physical properties under long-term natural vegetation restoration in the Loess Plateau of China, J. Arid Environ., 64, 77-96, 2006.

Liu, X. P., Chen, L. H., and Chen, J. H.: Study on the distribution of root density of Robinia pseudoacacia L. and Pinus tabulaeformis Carr, Arid Zone Research, 24, 647-651, 2007 (in Chinese).

Lugo, A. E.: The apparent paradox of reestablishing species richness on degraded lands with tree monocultures, For. Ecol. Manage., 99, 9-19, 1997.

Lu, R. K. (Eds.): Methods for Soil and Agriculture Chemistry Analysis, Chinese Agricultural Science and Technology Press, Beijing, China, 1999 (in Chinese).

Maestre, F. T., Bautista, S., Cortina, J., and Bellot, J.: Potential of using facilitation by grasses to establish shrubs on a semiarid degraded steppe, Ecol. Appl., 11, 1641-1655, 2001.

Marin-Spiotta, E., Silver, W. L., Swanston, C. W., and Ostertag, R.: Soil organic matter dynamics during 80 years of reforestation of tropical pastures, Global Change Biol., 15, 1584-1597, 2009.

Merino, A., Fernandez-Lopez, A., Solla-Gullon, F., and Edeso, J.
M.: Soil changes and tree growth in intensively managed $\mathrm{Pi}$ nus radiata in northern Spain, For. Ecol. Manage., 196, 393-404, 2004.

McVicar, T. R., Li, L. T., Van Niel, T. G., Zhang, L., Li, R., Yang, Q. K., Zhang, X. P., Mu, X. M., Wen, Z. M., Liu, W. Z., Zhao, Y. A., Liu, Z. H., and Gao, P.: Developing a decision support tool for China's re-vegetation program: Simulating regional impacts of afforestation on average annual streamflow in the Loess Plateau, Forest Ecol. Manag., 251, 65-81, 2007.

Meng, Q. Q., Wang, J., and Wu, F. Q.: Slope soil moisture environment of acacia-forestland of the Loess Plateau, Agric. Res. Arid Areas, 26, 28-32, 2008 (in Chinese).

Nosetto, M. D., Jobbagy, E. G., and Paruelo, J. M.: Landuse change and water losses: the case of grassland afforestation across a soil textural gradient in central Argentina, Global Change Biol., 11, 1101-1117, 2005.

Pacala, S. and Socolow, R.: Stabilization wedges: Solving the climate problem for the next 50 years with current technologies, Science, 305, 968-972, 2004.

Parrotta, J. A., Knowles, O. H., and Wunderle, J. M.: Development of floristic diversity in 10-year-old restoration forests on a bauxite mined site in Amazonia, For. Ecol. Manage., 99, 21-42, 1997.

Paul, K. I., Polglase, P. J., Nyakuengama, J. G., and Khanna, P. K.: Change in soil carbon following afforestation, Forest Ecol. Manag., 168, 241-257, 2002.

Porto, P., Walling, D. E., and Callegari, G.: Investigating the effects of afforestation on soil erosion and sediment mobilisation in two small catchments in Southern Italy, Catena, 79, 181-188, 2009.

Puigdefàbregas J. and Mendizabal, T.: Perspectives on desertification: western Mediterranean, J. Arid Environ., 39, 209-224, 1998.

Qiu, Y., Fu, B. J., Wang, J., and Chen, L. D.: Soil moisture variation in relation to topography and land use in a hillslope catchment of the Loess Plateau, China, J. Hydrol., 240, 243-263, 2001.

Querejeta, J. I., Roldán, A., Albaladejo, J., and Castillo, V.: Soil water availability improved by site preparation in a Pinus halepensis afforestation under semiarid climate, Forest Ecol. Manag., 149, 115-128, 2001.

Resh, S. C., Binkley, D., and Parrotta, J. A.: Greater soil carbon sequestration under nitrogen-fixing trees compared with Eucalyptus species, Ecosystems, 5, 217-231, 2002.

Roberts, S., Vertessy, R., and Grayson, R.: Transpiration from Eucalyptus sieberi (L. Johnson) forests of different age, Forest Ecol. Manag., 143, 153-161, 2001.

Robichaud, P. R.: Fire effects on infiltration rates after prescribed fire in Northern Rocky Mountain forests, USA, J. Hydrol., 231, 220-229, 2000.

Sahin, V. and Hall, M. J.: The effects of afforestation and deforestation on water yields, J. Hydrol., 178, 293-309, 1996.

Schume, H., Jost, G., and Hager, H.: Soil water depletion and recharge patterns in mixed and pure forest stands of European beech and Norway spruce, J. Hydrol., 289, 258-274, 2004.

Shan, C. J., Liang, Z. S., and Hao, W. F.: Review on growth of locust and soil water in Loess Plateau, Acta Bot. Boreal.-Occident. Sin., 23, 1341-1346, 2003 (in Chinese).

Shangguan, Z. P.: Soil desiccation occurrence an its impact on forest vegetation in the Loess Plateau of China, Int. J Sust. Dev. World, 14, 299-306, 2007.

Soane, B. D.: The role of organic matter in soil compactibility: A 
review of some practical aspects, Soil Till. Res., 16, 179-201, 1990.

Sun, Z. F., Zhang, X. P., and Zhu, J. Z.: Growth of Robinia pseudoacacia in diferent density onslope in loess area in west of Shanxi province, System Sciences and Comprehensive Studies in Agriculture, 22, 46-49, 2006 (in Chinese).

Ter Braak, C. J. F.: The analysis of vegetation-environment relationships by canonical correspondence-analysis, Vegetatio, 69, 69-77, 1987.

Van Dijk, A. and Keenan, R. J.: Planted forests and water in perspective, Forest Ecol. Manag., 251, 1-9, 2007.

Verhoef, A., Fernández-Gálvez, J., Diaz-Espejo, A., Main, B. E., and El-Bishti, M.: The diurnal course of soil moisture as measured by various dielectric sensors: Effects of soil temperature and the implications for evaporation estimates, J. Hydrol., 321, 147-162, 2006.

Vertessy, R. A., Watson, F. G. R., and O'Sullivan, S. K.: Factors determining relations between stand age and catchment water balance in mountain ash forests, Forest Ecol. Manag., 143, 13-26, 2001.

Wang, B. T., Wang, Y., Guo, J. H., Zheng, P. L., Ma, F. B., and Zhang, H.: Effect on biomass of stand density of aritificial black locust forest in semi-arid region of Loess Plateau, Sci. Soil Water Conserv., 3, 35-39, 2005 (in Chinese).

Wang, J. B., Ji, Z. P., Bai, L. Q., Xiao, Y. R., and Su, Y. Q.: The relation between soil organic carbon and root biomass in plantation, Journal of Noflhwest Forestry University, 22, 54-56, 2007 (in Chinese).

Wang, J. X., Wang, D. H., and Liu, G. Q.: Distribution characteristics of effective root density in the planted Robinia pseudoacacia and Platycladus orientalis forest site, Acta Bot. Boreal.-Occident. Sin., 24, 2208-2214, 2004a (in Chinese).
Wang, L., Shao, M. A., and Zhang, Q. F.: Distribution and characters of soil drylayer in north Shaanxi Loess Plateau, Chin. J. Appl. Ecol., 15, 436-442, 2004b (in Chinese).

Watts, C. W. and Dexter, A. R.: The influence of organic matter in reducing the destabilization of soil by simulated tillage, Soil Till. Res., 42, 253-275, 1997.

Wright, J. A., DiNicola, A., and Gaitan, E.: Latin American forest plantations - Opportunities for carbon sequestration, economic development, and financial returns, J. For., 98, 20-23, 2000.

Wu, S. H., Zhu, Q. K., Yu, X. X., and Zhang, X. P.: Calculation and analysis of proper stand density of main afforestation species in western Shanxi of Loess Plateau, Res. Soil Water Conserv., 14, 386-388, 2007 (in Chinese).

Wu, Z. Y. (Eds.): Vegetation of China, Science Press, Beijing, China, 1980 (in Chinese).

Yang, W. Z. and Yu, C. Z. (Eds.): Regional Control and Assessment to the Loess Plateau, Science Press, Beijing, China, 1990 (in Chinese).

Yang, X. H., Jia, Z. Q., and Ci, L. J.: Assessing effects of afforestation projects in China, Nature, 466, 315-315, 2010.

Yin, J., Qiu, G. Y., He, F., He, K. N., Tian, J. H., Zhang, W. Q., Xiong, Y. J., Zhao, S. H., and Liu, J. X.: Leaf area characteristics of plantation stands in semi-arid loess hill-gully region of China, J. Plant Ecol., 32, 440-447, 2008 (in Chinese).

Zhang, X. Z.: Study on the composition of soil particles and texture zoning of the Loess Plateau, Soil and Water Conservation in China, 3, 11-13, 2002 (in Chinese).

Zhao, J. B. and Li, Y. Q.: Effects of soil-drying layer on afforestation in the Loess Plateau of Shaanxi, Journal of Desert Research, 25, 370-373, 2005 (in Chinese). 